\section{Inhibition of Mould Growth by p-Aminobenzoic Acid and the n-Butyl Ester}

In tests conducted in these laboratories, $p$-aminobenzoic acid and the $n$-butyl $p$-aminobenzoate have shown definite reduction in rate of growth of three representative moulds (species of Aspergillus, Penicillium and Byssochlamys) growing on Czapek-Dox agar medium, $p H$ 4. Inhibition in the case of the free acid was very marked (at least 50 per cent) at a concentration of $5 \cdot 6$ millimolar $(\mathrm{mm}$.) and a reduction could still be detected, in the case of Aspergillus, as low as $0.18 \mathrm{~mm}$. The butyl ester proved more effective, greater than 70 per cent reduction being observed at $1.0 \mathrm{~mm}$. and a marked effect persisting as low as $0.14 \mathrm{~mm}$.- the lowest concentration tested. In cases of the intermediate and lower concentrations of the free acid, the colonies remained regular in outline and maintained a steady though reduced rate of increase; concentrations $9 \cdot 8$ and $5.6 \mathrm{~mm}$. gave rise to very irregular and fluctuating growth. With the higher concentrations of both substances, particularly of the $p$-aminobenzoic acid, an orangeyellow pigmentation was observed both in the mycelial felt and in the surrounding medium ${ }^{1,2}$.

With interest largely focused on the anti-sulphonamide and growth-factor effects of $p$-aminobenzoic acid and the fact that these are shown at extreme dilutions, it is not surprising that observations of inhibition by this substance have been relatively few. Woods ${ }^{3}$ has actually referred to a slight inhibition of bacteria at concentrations (unspecified) above $0.2 \mathrm{~mm}$. Most workers have been concerned with lower maximum concentrations than this, although Mayer ${ }^{2}$ does not report inhibition of Mycobacterium tuberculosis when working at concentrations as high as $7 \cdot 3 \mathrm{~mm}$. Tamura ${ }^{4}$ has, however, found inhibition with Bacterium tularense at $0.5 \mathrm{~mm}$. and complete absence of growth after eight days at $1.0 \mathrm{~mm}$. Johnson et al. ${ }^{5}$ found evidence of both stimulation and inhibition of luminescent bacteria according to the concentration of $p$-aminobenzoic acid in the different parts of the treated growth. Lee and Foley ${ }^{8}$ have made the interesting observation that raised temperatures can cause inhibition of bacterial growth by $p$-aminobenzoic acid at concentrations as low as $0.01 \mathrm{~mm}$., as well as failure to show anti-sulphonamide action. Lavor and Ferguson ${ }^{7}$ record harmful effects on protozoa by concentrations of $p$-aminobenzoic acid $(7 \cdot 3-0 \cdot 073 \mathrm{~mm}$.), comparable with those reported above as effective against moulds.

Esters of $p$-aminobenzoic acid have also been regarded principally from the point of view of growth factor and anti-sulphonamide activity. These include simple alkyl esters ${ }^{3,8,9}$ and local anæsthetics of the procaine type ${ }^{10,11,12}$. Kuhn et al. ${ }^{9}$ include some results with such esters. Their experience of the butyl ester differs from ours with fungi, in that they report it, together with the ethyl, lauryl and cetyl esters, as having no bacteriostatic effect with Streptobacterium plantarum when studied up to approximately $12 \mathrm{~mm}$. (This would, according to our experience, be greatly in excess of the solubility of the butyl ester.)

Other compounds related to $p$-aminobenzoic acid should be mentioned. Both Hirsch ${ }^{13}$ and Kuhn et al. ${ }^{9}$ have reported inhibition by $p$-aminobenzamide; the former found it almost as active as sulphanilamide at comparable concentrations, the latter noted growth accelerations at greater dilutions $(0.007 \mathrm{~mm}$.) but
50 per cont inhibition at $0.014 \mathrm{~mm}$. Auhagen ${ }^{14}$ reports relatively weak sulphonamide-like inhibition with $p$-aminoacetophenone and $p$-aminobenzophenone. Other workers ${ }^{15,16}$ have studied a number of substituted $p$-aminobenzoic acids, and have found that according to the nature and position of the substituents, some of the compounds demonstrated sulphonamide-like bacteriostasis, some retained $p$ aminobenzoic acid properties, while others were practically inactive.

Such results as those reviewed above, taken with our own experience with moulds, suggest that more attention might be given to the inhibitory action of $p$-aminobenzoic acid and its derivatives. On one hand, increasing the concentration of $p$-aminobenzoic acid gives rise to definite inhibition. On the other, stimulation by sulphanilamide has been observed in low enough concentrations ${ }^{5,17}$. Compounds like sulphanilamide and $p$-aminobenzoic acid might profitably be regarded as members of the same broad biochemical group possessing a similar 'pattern' of inhibitory properties : showing quantitative rather than qualitative differences in their toxic behaviour.

Evidence of its toxic properties raises the question as to the form in which $p$-aminobenzoic acid is likely to occur in the cell. It seems probable that some at least is built into a larger 'non-toxic' molecule. Recently the existence of 'bound' forms of $p$-aminobenzoic acid in naturally occurring material has been postulated 18,19,20. According to Blanchard's evidence ${ }^{20}$ the amino group is likely to be involved in a peptide link. Ratner and others are reported ${ }^{21}$ as having isolated from yeast a polypeptide containing one molecule of $p$-aminobenzoic acid and some thirteen molecules of $l-(+)$ glutamic acid.

Further systematic investigations of $p$-aminobenzoic acid and related compounds are being conducted in these laboratories.

G. W. K. Cavill.

Chemistry Department,

Sydney Technical College.

School of Agriculture,

University of Sydney, Sydney.

Nov. 30.

${ }^{1}$ Mayer, R. L., Science, 98, 203 (1943)

${ }^{2}$ Mayer, R. L., J. Bact., 48, 93 (1944).

3 Woods, D. D., Brit. J. Exp. Path., 21, 74 (1940).

- Tamura, J. T., J. Bact., 47, 529 (1944).

${ }^{5}$ Johnson F. H., Carver, C. M., Harryman, W. K., J. Bact., 44, 703 (1942).

${ }^{6}$ Lee, S. W., and Foley, E. J., Proc. Soc. Exp. Biol. Med., 53, 243 (1943).

${ }^{7}$ Lavor, E. M., and Ferguson, F. F., J. Elisha Mitchell Sci. Soc., 58, 166 (1942); C.A., 37, 2083 (1943).

${ }^{8}$ Kuhn, R., and Schwarz, K., Ber., 74B, 1617 (1941) ; Chem. Abs., 37, 357 (1943).

- Kuhn, R., Moller, E. F., Wendt, G., and Beirnert, H., Ber., 75B, 711 (1942); Chem. Abs., 36, 7017 (1942).

${ }^{10}$ Rubbo, S. D., and Gillespie, J. M., Nature, 146, 838 (1940).

${ }^{11}$ Landy, M., and Dicken, D. M., J. Biol. Chem., 146, 109 (1942).

${ }_{12}$ Goetchius, G. R., and Lawrence, C. A., J. Bact., 47, 450 (1944).

13 Hirsch, J., Science, 96, 139 (1942).

14 Auhagen, E., Z. physiol. Chem., 274, 48 (1942); Chem. Abs., 37, 5100 (1943).

${ }^{15}$ Wyss, O., Rubin, M., and Strandskov, F. B., Proc. Soc. Exp. Biol. Med., 52, 155 (1943).

${ }^{16}$ Johnson, O. H., Green, D. E., and Pauli, R., J. Biol. Chem., 153, 37 (1944).

17 Lamanna, C., and Shapiro, I. M., J. Bact., 45, 385 (1943).

${ }^{18}$ Lewis, J. C., J. Biol. Chem., 148, 441 (1942).

19 Thompson, R. C., Isbell, E. R., and Mitchell, H. K., J. Biol. Chem., $148,281(1943)$

20 Blanchard, K. C., J. Biol. Chem., 140, 919 (1941).

${ }_{21}$ Green, D. E., and Stumpf, P. K., Ann. Rev. Biochem., 13, 1 (1944). 